\title{
A PLURALIDADE DE VOZES NO REPÓRTER CBN E O MOVIMENTO DO DISCURSO "SUPOSTAMENTE INDIRETO"
}

\section{Lídia Ramires ${ }^{(*)}$}

Resumo: O espaço entre as diversas vozes presentes no jornalismo de rádio tem sido observado basicamente pela Comunicação Social. A preocupação em evitar a confusão e prejudicar a compreensão por parte dos ouvintes está em manuais de radiojornalismo e estudos sobre a estrutura do texto para rádio. Com a Internet, as emissoras de rádio passaram a disponibilizar o conteúdo de seus noticiários, possibilitando a observação do funcionamento do discurso veiculado. No site da Central Brasileira de Notícias (CBN) - escolhida como veículo-alvo de estudo por, desde sua fundação em 1991, se propor a trabalhar como central radiojornalística de abrangência nacional - pode-se verificar que, ao inserir em seu noticiário trechos do discurso do outro, o redator/locutor utiliza o discurso indireto marcado por glosas e insere declarações diretas por meio de aspas. Na perspectiva da Análise do Discurso de linha francesa, será analisado o pluralismo de vozes no noticiário da Repórter CBN - noticiário veiculado diariamente, de hora em hora, em rede nacional -, disponibilizado, por escrito na página da CBN na Internet, e como as glosas não são apenas marcas de discurso indireto, mas pode apanhar o discurso direto.

Palavras-chave: discurso, pluralidade de vozes, discurso do outro

\section{Fundamentação Teórica}

No jornalismo de rádio é constante a preocupação de não confundir o ouvinte, de não prejudicar a compreensão da notícia. $\mathrm{O}$ texto claro, conciso, breve é característica do veículo de comunicação.

O ouvinte da notícia de rádio é obrigado a realizar um exercício de transformação das informações sonoras transmitidas em imagens visuais imaginárias. Essa transformação se dá graças à sugestão ${ }^{l}$ nos ouvintes, o que aumenta a sensação de participação nos

(*) Universidade Federal de Alagoas / CNPq.

1 O termo sugestão é tomado por Emílio Prado (1989) para explicar a transformação que o ouvinte faz de imagens sonoras em imagens visuais imaginárias. 
fatos noticiados. Segundo Prado (1989), "este sentido de participação e esta sugestão aumentam a credibilidade da notícia” (p.49).

A notícia de rádio, por essas especificidades apresentadas, foi estabelecida por Prado em três tipos: a notícia estrita, a mais freqüente, principalmente em noticiários de hora em hora; a notícia de citações "com voz", de estrutura geral semelhante à notícia estrita mas com a inclusão de trechos gravados, dados expressados pela voz de uma fonte, ou protagonista da notícia; por último, a notícia com entrevista, de estrutura diferenciada das demais, traz introdução atrativa e a apresentação de quem estará sendo entrevistado e sobre o quê irá se falar. Em seqüência, é apresentada uma entrevista com perguntas e respostas curtas.

Nossa proposta é de analisar as notícias estritas do Repórter $\mathrm{CBN}$, noticiário veiculado de hora em hora pela Central Brasileira de Notícias (CBN) - escolhida como veículo-alvo de estudo por se propor a trabalhar como central jornalística de abrangência nacional, com mais de 200 jornalistas em todo o Brasil e exterior. A CBN, rede integrante do Sistema Globo de Rádio, desde sua inauguração, em outubro de 1991 (Dias, 1999, p.65), implantou no Brasil um projeto all news (somente notícias), trabalhando, como se autodefine em suas chamadas institucionais: A rádio que toca notícia.

A pluralidade de vozes no noticiário da CBN demonstra a busca pela credibilidade ao fato noticiado, ao estimular a sensação de participação de que Prado fala. Em nossa análise pode-se verificar que, ao inserir em seu noticiário trechos do discurso do outro, o redator/locutor utiliza o discurso indireto marcado por glosas e insere declarações diretas por meio de aspas.

No texto de rádio, o uso de aspas deve ser evitado. Como sugere Barbeiro (2001, p.64), o uso de aspas, "além de dificultar a entonação pelo locutor, pode dar ao ouvinte a impressão de que o texto é opinativo". Ao afirmar que o ouvinte pode ter a "impressão" de que o texto não é informativo, o autor aponta para a possibilidade de o locutor emprestar sua credibilidade ao texto do outro, podendo o ouvinte entender o texto como opinião do locutor.

Para Prado, o uso das aspas em textos radiojornalísticos modifica o sentido dos termos aos quais se aplicam, devendo, por isso. ser evitado. 

"SUPOSTAMENTE INDIRETO"

É muito difícil transmitir, através da entonação, a modificação exata que representam, e é por isso que não é aconselhável sua utilização. As aspas que se aplicam a citações textuais são um recurso gráfico que não tem tradução fônica e, portanto, não servem para a redação radiofônica (1989, p.31).

As análises feitas por Barbeiro e Prado, no entanto não observam a apreensão do discurso do outro. Para Bakhtin, a enunciação citada não pode ser tratada apenas como um tema do discurso, pois seria "caracterizá-la superficialmente" (1992, p.144). Para entrar em seu conteúdo seria necessário integrá-lo na construção do discurso. Ainda segundo Bakhtin, o verdadeiro objeto de análise não pode ser apenas o "discurso de outrem", e sim a interação entre a dinâmica "do discurso a transmitir e aquele que serve para transmitilo" (p.148).

O uso das aspas pelo enunciador indica que, segundo Maingueneau (2001, p.162), "seu discurso não coincide consigo mesmo, porém não explica motivo". Para entender a razão do emprego das aspas e interpretá-las, o contexto precisa ser levado em consideração.

Realmente, a análise do uso de aspas, fora de seu contexto, seria impossível. Essa impossibilidade, como afirma Amaral:

significa reconhecer que a interpretação desse recurso no texto requer o reconhecimento das condições de produção do discurso, tanto no contexto mais imediato quem fala e em que circunstâncias, a situação imediata da enunciação -, como no contexto mais amplo - o momento histórico-conjuntural em que o texto foi produzido (2001, p.116).

Amaral observa essa necessidade, especificamente, nos textos publicados em jornais e revistas.

As noções de heterogeneidades enunciativas de AuthierRevuz mostram a inscrição do outro na seqüência discursiva, ao destacar as formas de heterogeneidade mostrada, da qual as aspas são um das formas; e de heterogeneidade constitutiva "do sujeito e de seu discurso". 
É a estrutura da língua que permite que, na linearidade de uma cadeia, se faça escutar a polifonia não intencional de todo discurso, através da qual a análise pode tentar recuperar os indícios da "pontuação do inconsciente" (1990, p.28).

Maingueneau (1993, p.91) afirma que "as aspas constituem antes de mais nada um sinal constituído para ser decifrado por um destinatário". Assim, ao utilizar as aspas, o sujeito é obrigado a realizar uma representação de seu leitor (em nosso caso, o ouvinte), mesmo que inconscientemente, e, simetricamente, oferece ao ouvinte não só uma certa imagem de si mesmo, como da posição daquele fala ao utilizar as aspas. Continua o autor, "cada decodificação realizada pelo destinatário reforça a conivência entre os parceiros do discurso, visto que estão partilhando a mesma forma de se situar no interdiscurso" (p.91).

distanciamento:

O mesmo autor ressalta ainda a ambigüidade do

o locutor citado aparece, ao mesmo tempo, como o nãoeu, em relação ao qual o locutor se delimita, e como a "autoridade" que protege a asserção. Pode-se dizer que "o que enuncio é verdade porque não sou eu que o digo", quanto ao contrário (p.86).

A opção por um discurso "supostamente indireto",, entendemos, contribui para o distanciamento do locutor e a transferência de responsabilidade de suas afirmações para os autores das declarações inseridas em seu discurso.

O uso de uma citação dentro do discurso direto é uma forma de ampliar este distanciamento, uma vez que coloca para o outro a responsabilidade para o que é dito.

Lemos explicou que o valor elevado se deve ao "ritmo normal de operações". (Repórter CBN, 12/11/03)

2 Propomos categorizar o discurso "supostamente indireto", uma vez que ele se diferencia do discurso indireto e aponta para um distanciamento ainda maior do locutor/redator. 
Quem afirma que o ritmo de investimento do BNDES é "normal" é o diretor da área de Planejamento do BNDES, Mauricio Borges Lemos. Lemos informou que a instituição deveria desembolsar 12 bilhões de reais nos dois últimos meses de 2003 e que até outubro, os desembolsos somaram 22 bilhões de reais.

O redator/locutor se distancia da informação ao utilizar o discurso indireto para apresentar a informação.

Lemos explicou que o valor elevado se deve ao "ritmo normal de operações". Segundo ele, por conta da troca de comando e da reforma interna, o BNDES ficou parado nos primeiros meses do ano. (Repórter CBN, 12/11/03)

Na perspectiva da Análise do Discurso, não interessa, como afirma Orlandi, a organização do texto e sim o quê o texto organiza em sua discursividade. Ao abordar o uso do discurso do outro na redação do texto a ser noticiado, os manuais de radiojornalismo apontam para uma impossibilidade: de se dissociar sujeito e produção de sentidos. Como afirma Orlandi (1996, p.57), eles são inseparáveis, "ao produzir sentido, o sujeito se produz, ou melhor, o sujeito se produz, produzindo sentido". Assim a ilusão referencial de literalidade se cria no equívoco, como condição do significar. Observar o texto de rádio fora de uma perspectiva discursiva é empobrecer suas possibilidades e silenciar a riqueza do caráter histórico e ideológico na produção de sentidos.

\section{Site CBN}

A Rede CBN, integrante do Sistema Globo de Rádio, transmite o Repórter CBN, em rede nacional. A CBN conta com uma equipe de mais de 200 jornalistas colaboradores por todo o país. A escolha da CBN justifica-se por ser uma rádio que, desde sua inauguração, em outubro de 1991 (DIAS, 1999, p.65), implantou no Brasil um projeto all news (somente notícias), trabalhando, como se autodefine em suas chamadas institucionais veiculadas durante a programação: A rádio que toca notícia.

Neste trabalho analisamos textos disponibilizados pela Rádio CBN em seu site ( $\underline{w w w . c b n . c o m . b r}$ ) após a veiculação na rádio a cada 30 minutos. As notícias ficam disponíveis para acesso apenas até que o próximo noticiário seja exibido na página. A CBN não disponibiliza 
em seu site - como é comum em jornais - arquivo de matérias divulgadas.

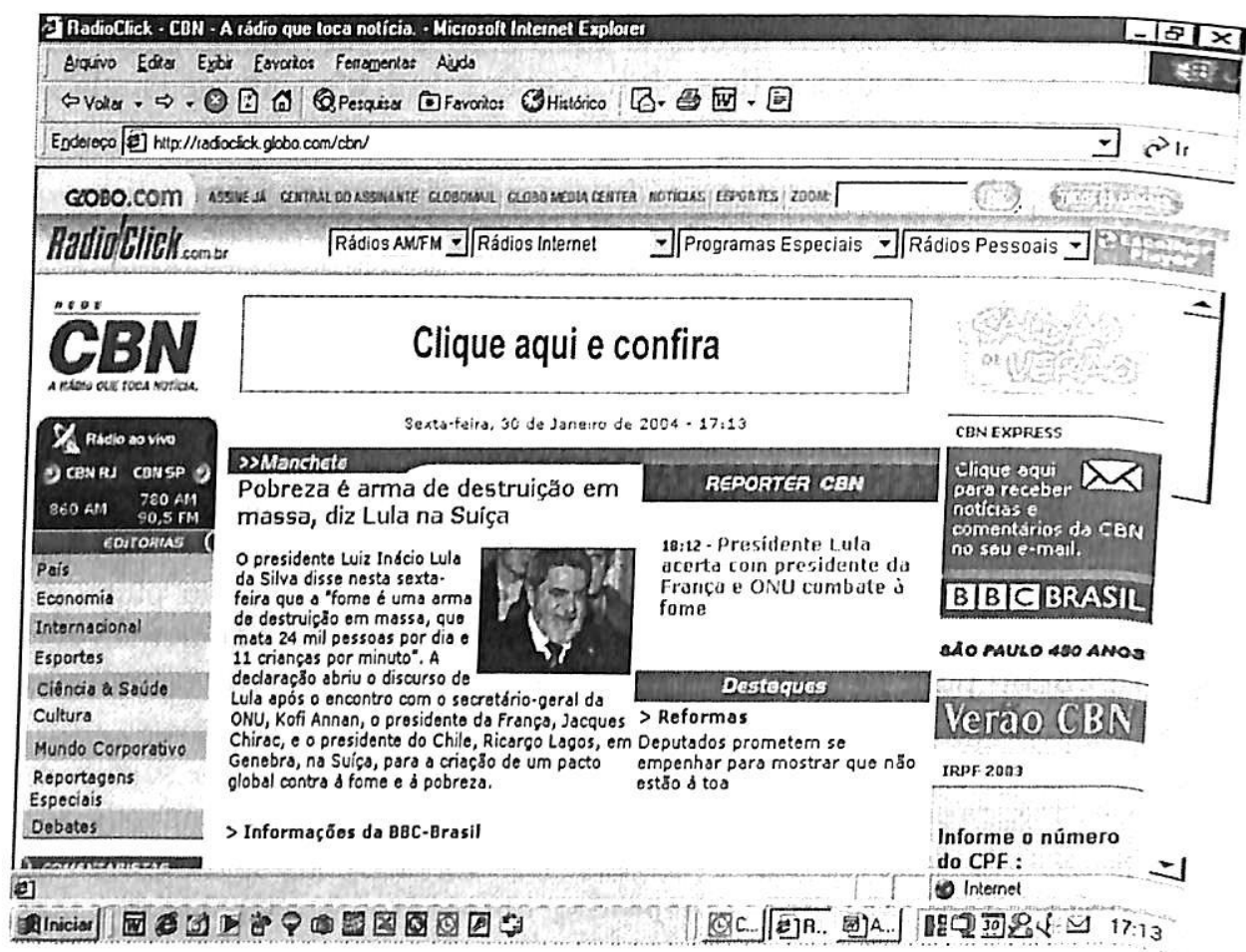

Figura 1 - Site da CBN

As seqüências discursivas analisadas neste trabalho são do arquivo interno da Rádio CBN São Paulo, cedidas pela direção da emissora para esta pesquisa. As notícias são redigidas e editadas previamente para veiculação no ar, seguindo o que Prado (1989) define como notícia estrita, que em contraste a pirâmide invertida da imprensa, não apresenta uma introdução com lide ${ }^{3}$ e informações em distribuição decrescente de importância. No rádio, a notícia estrita tem características específicas.

Encabeça a estrutura da notícia uma 'introdução', termo que utilizamos no lugar de 'lide' [...]. A introdução deve

3 O lide reúne as informações mais importantes do texto e responde às perguntas Quem? Quando? Onde? Como e Porque? . 
ser breve e simples em sua formulação. Sua função é a de atrair a atenção do ouvinte sobre aquela informação. [...] Após a introdução, na estrutura da notícia irradiada, seguem-se parágrafos sucessivos com as mesmas características internas da simplicidade, brevidade e linearidade. (PRADO, 1989, p. 49-50).

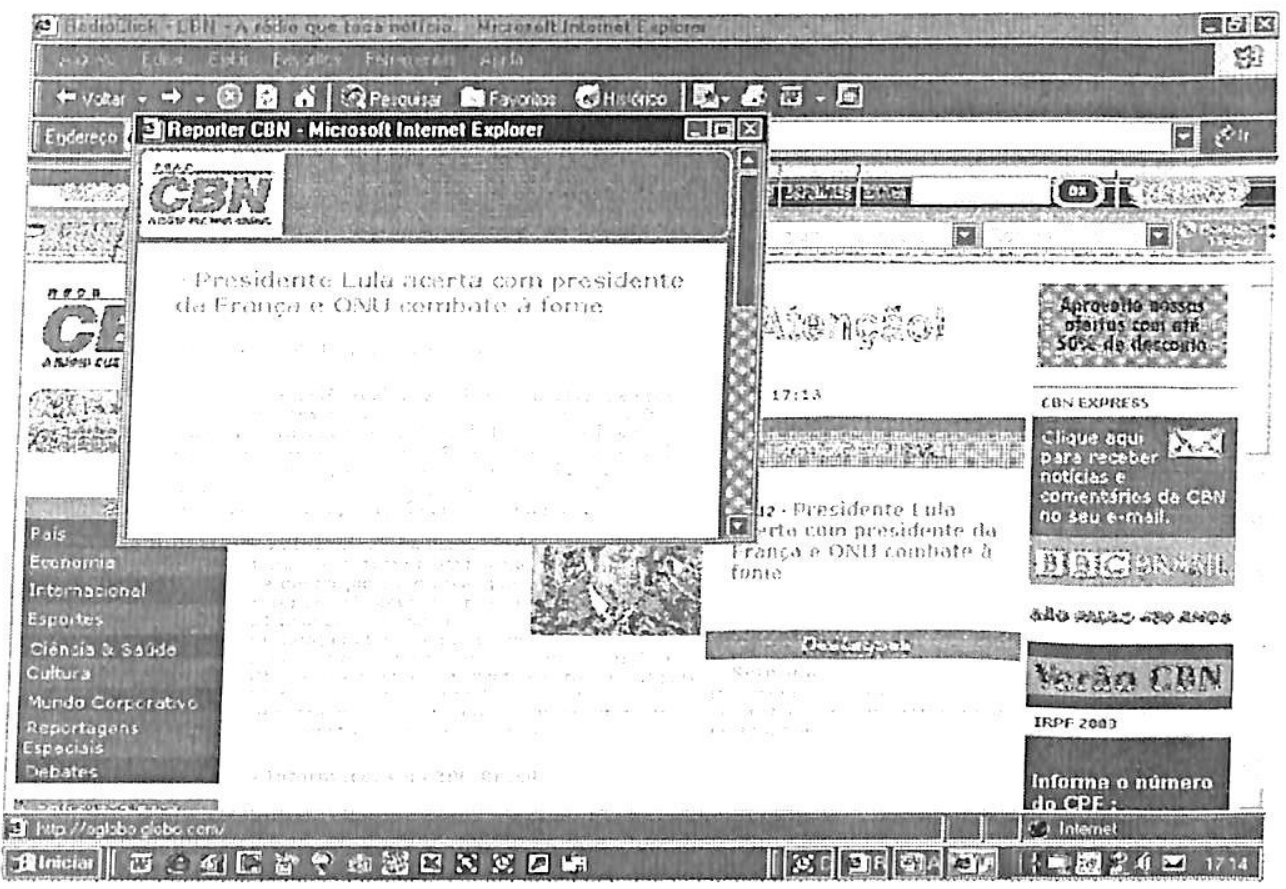

Figura 2 - Notícia estrita no Repórter CBN (destaque)

Análise

As seqüencias discursivas apresentadas nesta parte do trabalho são um recorte do corpus de nossa dissertação, que reúne enunciados veiculados no Repórter CBN sobre a eleição presidencial de 2002, ao fim do primeiro ano do governo do presidente Lula. 
Para fundamentar nossa análise trazemos de jornais impressos recortes das notícias divulgadas pela $\mathrm{CBN}$, destacando as citações dos personagens ${ }^{4}$.

\section{Seqüência discursiva 1}

O ministro da Previdência afirmou hoje que o governo não quer, com a taxação dos inativos, demonizar o servidor e nem cobrar a contribuição dos "pobres velhinhos do setor público". Ricardo Berzoini disse que busca reverter, de maneira tímida, o sistema previdenciário, que só beneficia 950 mil servidores civis e militares (Repórter CBN, 21/05/03).

A notícia trata da polêmica acerca da Reforma da Previdência Social. A declaração do ministro da Previdência, Ricardo Berzoini, pode ser observada desde o uso do primeiro verbo dicendi afirmou. Entretanto o que nos chama a atenção é a declaração, entre aspas que atribui aos aposentados a expressão "pobres velhinhos do setor público".

A notícia estrita é apresentada sob forma de discurso indireto "O ministro da Previdência afirmou hoje que o governo não quer, com a taxação dos inativos, demonizar (...)", mas insere os "pobres velhinhos do setor público", afasta a responsabilidade do locutor ao colocar, recortada do contexto, a declaração sob a responsabilidade de Berzoini. A conclusão da notícia retoma a forma de discurso indireto inicial.

Não só o tema, Reforma da Previdência, como o fato de se tratar de uma declaração da presidência, remete ao acontecimento de 11 de maio de 1998, quando o então presidente Fernando Henrique Cardoso afirmou: "pessoas que se aposentam com menos de 50 anos são vagabundos, que se locupletam de um país de pobres e miseráveis".

Ao inserir, no corpo da notícia estrita, o discurso direto, entre aspas, do ministro da Previdência, o redator/locutor reforça a conivência de que trata Maingueneau, ao partilhar com seus ouvintes a mesma forma de se situar no interdiscurso. O cenário apresentado, dos

Termo retirado do Jornalismo, que entende como personagem o sujeito parte do fato noticiado. 

"SUPOSTAMENTE INDIRETO"

"pobres velhinhos do setor público", e de não "demonizar o servidor", convoca o aposentado vagabundo, que "[se]torna rico, em geral, por meios pouco honestos", o pouco honesto que enriquece e tira dos pobres e miseráveis.

A notícia traz ainda uma generalização ao destacar que o sistema previdenciário só beneficia "950 mil servidores civis e militares", apagando as especificidades das regras que diferenciam a previdência de funcionários civis e militares.

A busca pela mesma notícia divulgada por jornais impressos, nos leva aos textos abaixo, das agências Folha (AF) e Brasil (ABr). A matéria traz as declarações de Berzoini no $15^{\circ}$ Fórum Nacional, na sede do Banco Nacional de Desenvolvimento Econômico e Social (BNDES).

\section{Previdência do servidor público é insustentável}

O Ministro da Previdência e Assistência Social, Ricardo Berzoini, reafirmou hoje, no Fórum Nacional, no BNDES, nesta capital, que o sistema da Previdência do servidor público é insustentável com as regras atuais. "É um sistema concentrador de renda, ainda que seja uma concentração de renda intraclasse de trabalhadores". Ele disse que a União precisa hoje arrecadar $\mathrm{R} \$ 23$ bilhões a mais por ano para subsidiar um sistema que atende apenas 950 mil aposentados civis e militares, o que gera desequilíbrio e é injusto do ponto de vista orçamentário.

O ministro criticou o atual sistema de previdência pública, na medida em que permite aposentadorias em idades inadequadas. Considerou mesmo um absurdo um país como o Brasil, independente da questão previdenciária, permitir que o Estado abra mão de uma procuradora, uma juíza, uma auditora fiscal com apenas 48 anos de idade, por aposentadoria, ainda mais que ela vai continuar a trabalhar em outra função no setor público ou no setor privado. O mesmo absurdo ocorre com os homens aos 53 anos, acrescentou.

5 Definição do Dicionário da Língua Portuguesa, de Aurélio Buarque de Hollanda (1989) para locupletar. 
"O Brasil não é um país que disponha dessa renda para subsidiar aposentadorias precoces. É um país que, com certeza, precisa desses quadros permanecendo no setor público para gerar a contrapartida mais do que justa do que aprenderam no serviço público", afirmou.

Afirmou que uma conta simples efetuada nesse sistema de repartição, que não é de capitalização, permite ver que um homem que contribua ao longo de 35 anos, dos 18 aos 53 anos, com salário de R\$ 2 mil, se contribuir com $11 \%$ e a União colocar mais $22 \%$, ele acumulará de contribuições nesse período, sem capitalização, R\$278 mil. O Estado retribuirá essa pessoa, se ela viver 27 anos após aposentar, obedecendo à expectativa de vida prevista, com recursos de R\$702 mil. Segundo Berzoini, isso revela a existência de um subsídio, uma situação em que o trabalhador não precisa necessariamente desse tipo de proteção porque está aposentando precocemente.

Outro caso ainda mais dramático, segundo o ministro, é o de uma pessoa que dos 16 aos 23 anos contribua para o INSS com um salário mínimo e dos 23 aos 38 anos esteja numa situação de trabalhador administrativo do setor público, com $\mathrm{R} \$ 1,2$ mil de salário e depois, aos 38 anos, tendo curso superior, passe num concurso para procurador e ganhe $\mathrm{R} \$ 6 \mathrm{mil}$, e dos 48 aos 53 anos passe a ganhar R\$ 8 mil. Sua contribuição acumulada será de $R \$$ 512 mil e a sua retribuição da ordem de $\mathrm{R} \$ 1,560$ milhão. "Se esse servidor gerar uma pensão para sua cônjuge com mais de 20 anos, teremos uma despesa adicional de $\mathrm{R} \$ 2,080$ milhões, num país que não tem dinheiro para a educação de maneira adequada, para a saúde, saneamento básico, moradia popular e outras políticas sociais fundamentais", avaliou.

Assegurou que, "portanto, não se trata, como muitos tentam caracterizar, de demonizar o servidor, de querer cobrar contribuição dos pobres velhinhos inativos do setor público". Trata-se, simplesmente, disse Berzoini, de buscar reverter, ainda que de maneira tímida - porque, se dependesse só de sua opinião, seria mais forte - o quadro grave, e de uma reforma estrutural com a criação da previdência complementar para os servidores públicos futuros. Além da vantagem de permitir uma melhor realidade atual no financiamento da previdência desses servidores, a reforma propiciará no futuro a acumulação de poupança previdenciária, ou seja, de poupança interna de boa 
qualidade para investimentos fundamentais em áreas importantes no país, "desde que bem fiscalizada, bem supervisionada e bem administrada, como é o objetivo nosso em relação à previdência complementar de todos os segmentos". (21/5/03, Agência Brasil)

\section{Berzoini acha proposta branda}

Rio de Janeiro - O ministro da Previdência, Ricardo Berzoini, afirmou ontem no Rio que a reforma que o Governo enviou ao Congresso é "amena" e que, no que dependesse apenas dele, seria ainda "mais dura". Berzoini fez as declarações ao participar do $15^{\circ}$ Fórum Nacional, na sede do Banco Nacional de Desenvolvimento Econômico e Social (BNDES).

No encontro, o deputado federal Roberto Brant (PFLMG), ministro da Previdência na gestão do presidente Fernando Henrique Cardoso, elogiou e classificou como "corajosa" a proposta do Governo Lula. Segundo Berzoini, a reforma da Previdência poderia ser ainda mais dura, levando em conta o quadro apresentado por ele no fórum: "É uma reforma que tem um caráter bastante ameno em relação ao que revelam as contas públicas".

Para o ministro, o objetivo da reforma não é "demonizar" os servidores públicos. "Não se trata, como muitos tentam caracterizar, de demonizar o servidor ou de querer cobrar contribuição dos pobres velhinhos inativos do setor público. Trata-se de buscar reverter, ainda que de maneira tímida, um quadro grave.

Forte

Ele disse não concordar com a avaliação de que a reforma seja muito forte. "Muitos consideram a reforma forte. Eu diria que, se dependesse só da minha opinião, ela seria um pouco mais forte", afirmou o ministro, sem especificar que pontos da reforma deveriam, para ele, ser mais fortalecidos. Logo após a apresentação do atual ministro da Previdência, o ex-ministro Roberto Brant comentou a proposta enviada pelo atual Governo ao Congresso.

Brant fez algumas críticas ao projeto, mas afirmou que defende que o PFL, hoje na oposição, vote a favor da reforma. "É 
uma proposta corajosa, audaciosa e que vai na direção certa, mas que tem algumas imperfeições", disse. (Agência Folha, 22/05/03)

A matéria da $\mathrm{AF}$ enfoca, no lide, a opinião do ministro Berzoini de que o texto da Reforma da Previdência, enviado ao Congresso é brando. Enquanto que o lide da $\mathrm{ABr}$ ressalta que, segundo o ministro, o "sistema da Previdência do servidor público é insustentável com as regras atuais". A matéria enfoca a preocupação do ministro com as aposentadorias precoces no serviço público.

As duas matérias trazem a declaração, entre aspas, de Berzoini de que o objetivo da reforma não é "demonizar" os servidores públicos, os "pobres velhinhos".

Além de apresentar a opinião de Berzoini, a matéria da AF noticia o apoio do deputado federal Roberto Brant (PFL-MG), ministro da Previdência no governo de Fernando Henrique Cardoso. Para o deputado federal do PFL, historicamente opositor do PT, a proposta é "corajosa". A oposição entre "branda", na opinião de Berzoini e "corajosa", na de Brant, na verdade aponta para a concordância de um ex-ministro da Previdência de FHC sobre a proposta de reforma do Governo Lula. Ao afirmar que a reforma, além de corajosa, é "audaciosa e que vai na direção certa, mas que tem algumas imperfeições", Brandt apresenta uma possibilidade de divergência que não é explicitada nem aprofundada no texto. Ao calar que "imperfeições" seriam estas, o texto ressalta apenas seu apoio à reforma.

Ao analisarmos o uso de discurso "supostamente indireto", temos que considerar também as seqüências em que o discurso indireto é utilizado no noticiário da Rádio CBN:

Seqüência discursiva 2

O vice-líder do PT, deputado Beto Albuquerque, garantiu que a votação do relatório será encerrada hoje na Comissão. Ele disse acreditar que a matéria poderá ser votada daqui a duas semanas, em primeiro turno, no plenário da Câmara. .(Repórter CBN, 05/09/03)

As declarações, precedidas dos verbos garantir e dizer, não trazem trechos entre aspas, e creditam as informações ao deputado Beto Albuquerque. $\mathrm{O}$ distanciamento do redator/locutor e a 
transferência da responsabilidade com o conteúdo das declarações são reforçados, sem que haja o uso de aspas, pela garantia do deputado e o fato de ele acreditar que a matéria irá à votação dentro de duas semanas.

\section{Conclusão}

A pluralidade de vozes no jornalismo da Rádio CBN está nas marcas lingüísticas que mostram não só o uso de glosas no discurso indireto, como também no uso de um discurso "supostamente indireto", por meio de declarações entre aspas.

Ao optar por inserir um discurso direto dentro do discurso indireto, o redator/locutor reforça a idéia de distanciamento e da transferência da responsabilidade das informações divulgadas por ele para os autores das declarações.

O fato de o uso do discurso "supostamente indireto" não ser prática comum no noticiário da Rádio $\mathrm{CBN}$, portanto fugindo do padrão da emissora e das normas dos manuais de radiojornalismo, nos mostra a contribuição de estudos discursivos do jornalismo desvelando a opacidade do discurso e, a partir da materialidade dos textos, o papel dos sujeitos do processo de comunicação (locutor e ouvinte) e a relação entre discursos na produção de sentidos.

\section{Referências}

AMARAL, Maria Virgínia Borges. Elementos para uma introdução à análise do discurso. Maceió: Ufal, 2001 (Texto inédito).

AMARAL, Maria Virgínia Borges. Demarcações do lugar do outro no discurso: a função discursiva das aspas. In: MOURA, Denilda (Org.). Língua e ensino: dimensões heterogêneas. Maceió, Edufal, 2000.

AMARAL, Maria Virgínia Borges. A (des)razão do mercado: efeitos de mudança no discurso da qualidade total. Tese de doutorado. Maceió: UFAL, 1999.

AUTHIER-REVUZ, Jacqueline. Heterogeneidade(s)enunciativa(s). Cadernos de Estudos Linguiísticos, n.19. Campinas: Unicamp, p.2542, 1990.

BAKHTIN, Mikhai. Estética da criação verbal. São Paulo: Martins Fontes, 1992b. 
BAKHTIN, Mikhail. Marxismo e filosofia da linguagem. 6. ed. Tradução de Michel Lahud e Yara Frateschi Vieira. São Paulo: Hucitec, 1992.

BARBEIRO, Heródoto. Manual de radiojornalismo. Rio de Janeiro: Campus, 2001.

DIAS, Carlos E.M. A rádio que toca notícias. In: MOREIRA, Sônia V. (Org.). Rádio no Brasil: tendências e perspectivas. Rio de Janeiro: EDUERJ; Brasília: Unb, 1999.

MAINGUENEAU, Dominique. Novas tendências na análise do discurso. 5. ed. Campinas: Pontes, 1993.

MAINGUENEAU, Dominique Análise de textos de comunicação. Tradução de Cecília P. de Souza-e-Silva e Décio Rocha. São Paulo: Cortez, 2001.

ORLANDI, Eni. As formas do silêncio: no movimento dos sentidos. Campinas: Unicamp, 1992.

ORLANDI, Eni.Interpretação: autoria, leitura e feitos do trabalho simbólico. Petrópolis: Vozes, 1996.

ORLANDI, Eni. Discurso e texto: formação e circulação dos sentidos. Campinas: Pontes, 2001.

PÊCHEUX, Michel. Semântica e discurso. Uma introdução à obra de Michel Pêcheux. Campinas: Unicamp, 1988.

PÊCHEUX, Michel. $O$ discurso: estrutura ou acontecimento. Campinas, Pontes, 1990.

PRADO, Emilio. Estrutura da informação radiofônica. Tradução de Marco Antonio de Carvalho. Novas buscas em comunicações, v. 31. São Paulo: Summus, 1989. 